Petra Hauke (Hrsg.)

Freundeskreise und Fördervereine 
Praxiswissen

$+$ 


\section{Freundeskreise und Fördervereine}

Best Practice in Öffentlichen Bibliotheken

Herausgegeben von Petra Hauke

Mit einem Geleitwort von Sinikka Sipilä,

Präsidentin des Weltbibliotheksverbandes IFLA 
Diese Veröffentlichung ist das Ergebnis einer Lehrveranstaltung des Instituts für Bibliotheks- und Informationswissenschaft der HumboldtUniversität zu Berlin, angeboten unter dem Titel „Von der Idee zum Buch - Durchführung eines Publikationsprojektes einschließlich DTP“ im Wintersemester 2014/2015 unter der Leitung von Petra Hauke. Die im Folgenden genannten Studierenden haben daran teilgenommen:

Gesa Baron, Mareike Fenja Bauer, Jacqueline Bayer, Julia Boltze, Cliff Buschhart, Samantha Degenkolb, Judith Feist, Keith Gruenewald, Kamil Jaworski, Daniel Jobs, Kristina Langrock, Daniela Müller, Astrid Neumann, Anika Röcker, Simone Schad, Thao Vuong Phan Phuong, Maria Waigant

Aus Gründen der besseren Lesbarkeit wird in den Texten in der Regel das generische Maskulinum dann verwendet, wenn kein biologisches Geschlecht gemeint ist (Sexus) oder männliche und weibliche Personen gleichermaßen gemeint sind (Genus, grammatisches Geschlecht). Dies beruht nicht auf einer Diskriminierung des weiblichen Geschlechts. Das Buch richtet sich gleichermaßen an Leserinnen und Leser.

ISBN 978-3-11-042654-0

e-ISBN (PDF) 978-3-11-042199-6

e-ISBN (EPUB) 978-3-11-042203-0

ISSN 2193-0198

\section{Library of Congress Cataloging-in-Publication Data}

A CIP catalog record for this book has been applied for at the Library of Congress.

\section{Bibliografische Information der Deutschen Nationalbibliothek}

Die Deutsche Nationalbibliothek verzeichnet diese Publikation in der Deutschen Nationalbibliografie; detaillierte bibliografische Daten sind im Internet über http://dnb.dnb.de abrufbar.

(C) 2015 Walter de Gruyter GmbH, Berlin/Boston Umschlagabbildung: Roman Antonov/iStock/thinkstock

Satz: Medien Profis GmbH, Leipzig

Druck und Bindung: Strauss GmbH, Mörlenbach

@ Gedruckt auf säurefreiem Papier

Printed in Germany

www.degruyter.com 